\title{
Coagulation of humic acid: The performance of preformed and non-preformed $\mathrm{Al}$ species
}

\author{
Baoyou Shi*, Qunshan Wei, Dongsheng Wang, Zhe Zhu, Hongxiao Tang \\ State Key Laboratory of Environmental Aquatic Chemistry, Research Center for Eco-Environmental Sciences, \\ Chinese Academy of Sciences, P.O. Box 2871, Beijing 100085, China
}

Received 22 June 2006; received in revised form 20 September 2006; accepted 22 September 2006

Available online 28 September 2006

\begin{abstract}
Inorganic polymeric $\mathrm{Al}$ coagulants have been being widely used in water treatment due to their advantages of applicability within broad $\mathrm{pH}$ and temperature ranges, high capacity of charge neutralization as well as less alkalinity consumption. However, the removal of dissolved organic matter (DOM) by such kind of coagulants has not been well understood because of the complexity of natural organic matter and the diversity of such polymeric Al coagulants. In this paper, coagulants with different $\mathrm{Al}$ speciation characteristics were prepared to conduct coagulation of humic acid (HA). The humic acid used was peat origin and was characterized physicochemically. The results showed that coagulants with preformed Al species were less effective than conventional Al salt in removing humic acid with large molecular and hydrophobic properties. The flocs formed by preformed Al species were smaller than those formed by conventional Al salt. Decreasing $\mathrm{pH}$ could improve the coagulation performance of all coagulants. Coagulation of humic acid might not follow the same charge neutralization rules associated with coagulation of mineral colloids. In the presence of humic acid, $\mathrm{Al}_{13}$ could be decomposed during coagulation process.
\end{abstract}

(c) 2006 Elsevier B.V. All rights reserved.

Keywords: Coagulation; Humic acid; Polyaluminum chloride; $\mathrm{Al}_{13}$

\section{Introduction}

Coagulation is one of the critical operation units for removing colloidal particles and dissolved organic matter (DOM) in surface water treatment. However, the mechanisms involved in colloidal particle and DOM removal could be significantly different. Charge neutralization and sweep flocculation (the incorporation of impurities in amorphous hydroxide precipitate) are considered to be the two most distinct mechanisms in removing mineral colloidal particles [1]. But much less has been understood on the mechanisms of DOM removal by coagulation. It was proposed that formation of insoluble complexes between DOM and coagulant species as well as the adsorption of DOM onto freshly formed hydroxide precipitate could be the determining mechanisms [2]. Due to the differences between coagulation of mineral colloids and DOM, the present designs and operating procedures that are effective for removing turbidity may not be the most effective for removing DOM [3].

\footnotetext{
* Corresponding author. Tel.: +86 10 62849138; fax: +86 1062923541 .

E-mail address: byshi@ rcees.ac.cn (B. Shi).
}

The commonly used conventional coagulants in water treatment include alum, sodium aluminate, ferric chloride, ferric sulfate, etc. Preformed polymeric metal coagulants have been shown to improve some of the coagulation performance compared to conventional coagulants [4-6]. Polymeric forms of metal coagulants in water treatment have become increasingly used due to their wider availability and reduction in cost [7]. Polyaluminum chloride (PACl) is one of the most important prehydrolyzed coagulants. $\mathrm{PACl}$ is less sensitive to changes in $\mathrm{pH}$ and temperature [8-10]. In addition, the high positive charge of some polycations, such as $\mathrm{Al}_{13}\left[\mathrm{AlO}_{4} \mathrm{Al}_{12}(\mathrm{OH})_{24}\left(\mathrm{H}_{2} \mathrm{O}\right)_{12}{ }^{7+}\right]$, is highly effective in neutralizing the negative charges of colloidal particles [11].

However, contradictory results have been reported concerning the effectiveness of PACl in DOM removal. Some researchers found that $\mathrm{PACl}$ was able to directly precipitate fulvic acids (FA) over a broad $\mathrm{pH}$ range and could be a better coagulant than alum at more acidic and basic $\mathrm{pH}$ values $[3,12]$. While some investigators observed that $\mathrm{PACl}$ did not reduce DOM as effectively as alum $[13,14]$.

The discrepancies related to the coagulation of DOM by $\mathrm{PACl}$ are mainly due to the complexity of DOM and the vari- 
ety of $\mathrm{PACl}$ products. DOM consists of a large number of organic compounds including natural and synthetic matters. Humic substances are ubiquitous in surface water and are the major organic constituent of unpolluted water. The molecular weight and hydrophobic/hydrophilic properties of humic substances are important factors associated with their treatment efficiencies [15]. Typically, humic substances are operationally divided into the more soluble fulvic acids and the less soluble humic acids (HA). On the other hand, most of PACl coagulants used in past studies were commercial products, and little is known about their exact chemical composition. The content of $\mathrm{Al}_{13}$ in commercial products is usually very low. In addition, $\mathrm{PACl}$ products from different manufacturers may contain different additives, such as sulfate and organic polymers.

The objective of this work was to get more understanding on the coagulation mechanisms of $\mathrm{PACl}$ in removal of humic substances by using well-characterized materials. Since more in-depth studies had been reported on the coagulation of fulvic acids, the emphasis of this paper was placed on the effect of $\mathrm{Al}$ species on the coagulation of humic acid. $\mathrm{AlCl}_{3}$, laboratory prepared $\mathrm{PACl}$ and purified $\mathrm{Al}_{13}$ were selected as coagulants with different speciation characteristics; a kind of peat humic acid was chosen to conduct the coagulation experiments and the humic acid was characterized by ultrafiltration and resin fractionation. To avoid the interference of some cations and anions in natural water (e.g. calcium, magnesium, sulfate, phosphate), synthetic test water was prepared to conduct the investigation.

\section{Materials and methods}

\subsection{Coagulants preparation and characterization}

All the reagents used to prepare each coagulant were of analytical grade and deionized water was used to make all solutions. The procedures of preparing each coagulant can be described as follows: (1) conventional $\mathrm{Al}$ salt $\left(\mathrm{AlCl}_{3}\right)$ : directly dissolving $\mathrm{AlCl}_{3} \cdot 6 \mathrm{H}_{2} \mathrm{O}$ into deionized water; (2) PACl: adding pre-determined amount of $\mathrm{Na}_{2} \mathrm{CO}_{3}$ slowly into $\mathrm{AlCl}_{3}$ solution under intense agitation. The temperature was kept at $70^{\circ} \mathrm{C}$ by using recycling water bath. The target basicity $(\mathrm{OH} / \mathrm{Al}$ molar ratio) of the $\mathrm{PACl}$ was 2.20 ; (3) $\mathrm{Al}_{13}$ : it was separated and purified from $\mathrm{PACl}$ using sulfate precipitation and nitrate metathesis reactions. The detailed procedures can be found in [16]. The total $\mathrm{Al}$ concentrations for all the coagulants were all adjusted to $0.1 \mathrm{~mol}^{-1}$. All the coagulants were stored in refrigerator after preparation for later use. No obvious turbidity appeared in the coagulant solutions during the study.

The speciation distributions of the three coagulants were characterized using both liquid-state ${ }^{27} \mathrm{Al}$ nuclear magnetic resonance (NMR) spectroscopy (Avance 500, Bruker, USA) and ferron colorimetric assay [8]. The ${ }^{27} \mathrm{Al}$ NMR patterns of the three coagulants are demonstrated in Fig. 1. The signal at $0 \mathrm{ppm}$ corresponds to monomeric species and the signal at $62.5 \mathrm{ppm}$ corresponds to $\mathrm{Al}_{13}$ species (only the central $\mathrm{Al}$ atom in $\mathrm{Al}_{13}$ structure can produce resonance signal), the signal at $80 \mathrm{ppm}$ is ascribed to the inner standard of $\mathrm{NaAl}(\mathrm{OD})_{4}$. Other $\mathrm{Al}$ species, such as colloidal species cannot be observed by ${ }^{27} \mathrm{Al}$ NMR. No

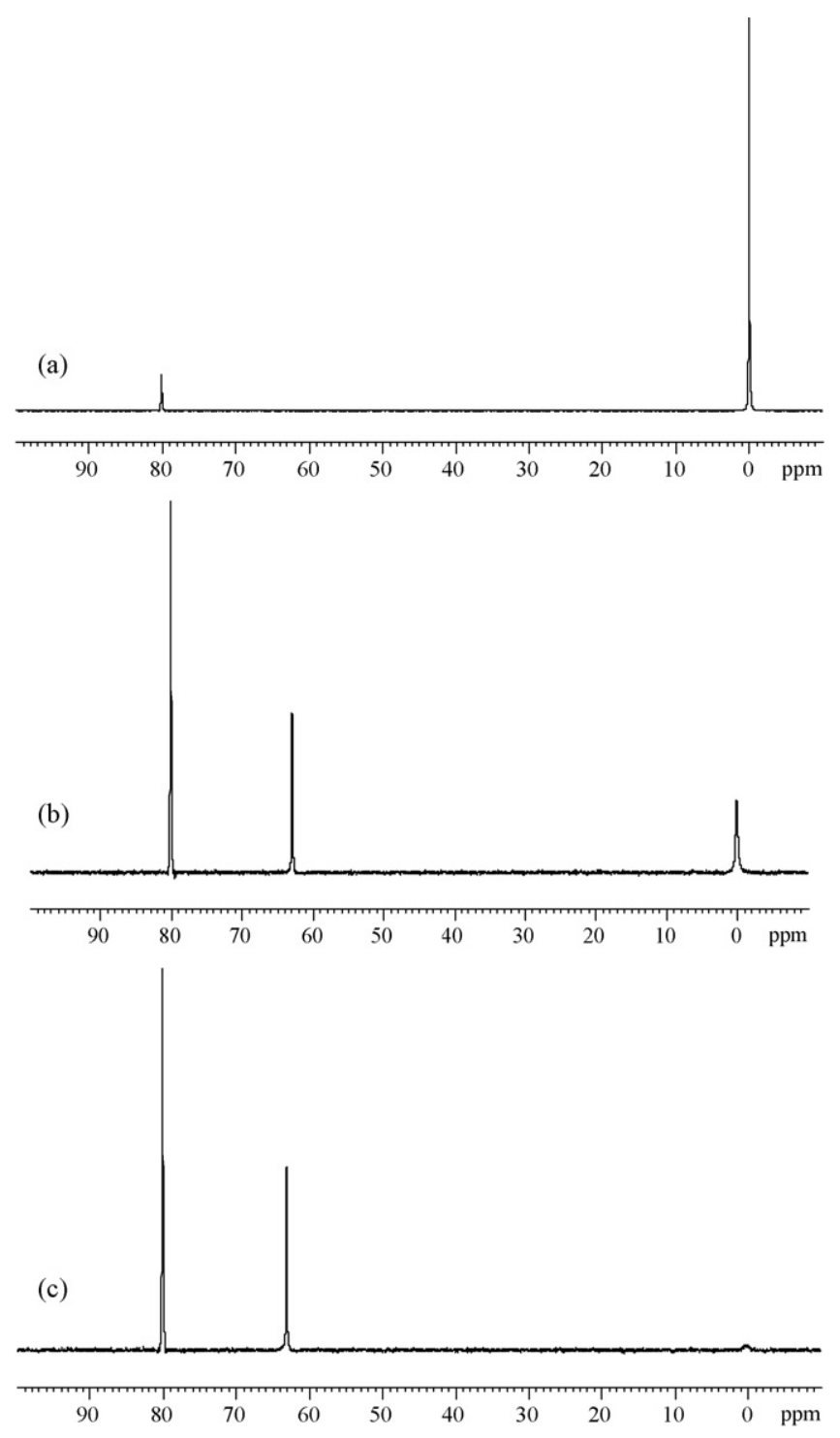

Fig. 1. ${ }^{27} \mathrm{Al}$ NMR patterns of three coagulants ((a) $\mathrm{AlCl}_{3}$; (b) $\mathrm{PACl}$; (c) $\mathrm{Al}_{13}$ ).

$\mathrm{Al}_{13}$ was detected from $\mathrm{AlCl}_{3}$ solution, and the predominant species in $\mathrm{AlCl}_{3}$ was monomers. Both $\mathrm{Al}_{13}$ and monomeric $\mathrm{Al}$ species existed in $\mathrm{PACl}$ while the content of monomers was relatively low. As to the purified $\mathrm{Al}_{13}$, the signal of monomeric species was almost negligible.

Ferron assay can differentiate Al species into three categories: $\mathrm{Al}_{\mathrm{a}}$, monomeric (possibly some oligomeric) species; $\mathrm{Al}_{\mathrm{b}}$, polymeric species which could be rationally regarded as $\mathrm{Al}_{13}$ in this study; $\mathrm{Al}_{\mathrm{c}}$, colloidal species. The speciation characteristics of three coagulants are listed in Table 1 . As evidenced by ${ }^{27} \mathrm{Al}$

Table 1

Species distribution of three different coagulants

\begin{tabular}{llccc}
\hline & $\mathrm{pH}$ & $\mathrm{Al}_{\mathrm{a}}(\%)$ & $\mathrm{Al}_{\mathrm{b}}(\%)$ & $\mathrm{Al}_{\mathrm{c}}(\%)$ \\
\hline $\mathrm{AlCl}_{3}$ & 3.28 & 91.7 & 8.3 & 0.0 \\
$\mathrm{PACl}$ & 4.02 & 6.2 & 29.5 & 64.3 \\
$\mathrm{Al}_{13}$ & 4.24 & 2.0 & 95.8 & 2.2 \\
\hline
\end{tabular}


NMR patterns, the $\mathrm{Al}$ monomers $\left(\mathrm{Al}_{\mathrm{a}}\right)$ of $\mathrm{AlCl}_{3}$ accounted for 91.7\%; while, the $\mathrm{Al}_{\mathrm{b}}$ component $\left(\mathrm{Al}_{13}\right)$ of purified $\mathrm{Al}_{13}$ was as high as $95.8 \%$; $\mathrm{PACl}$ was consisted of mixed species with $\mathrm{Al}_{\mathrm{C}}$ being the dominant species.

\subsection{Humic acid characterization}

In order to examine the coagulation behaviors of higher molecular and less soluble humic acid, commercially available peat humic acid (Tianjin, China) was purchased and characterized.

Preparation of stock solution: $1.40 \mathrm{~g}$ humic acid was dissolved in $1000 \mathrm{ml}$ of $0.01 \mathrm{moll}^{-1} \mathrm{NaOH}$ with $6 \mathrm{~h}$ of continuous stirring, then filtered through $0.45 \mu \mathrm{m}$ membrane filter and stored in refrigerator for later use.

Apparent molecular weight (AMW) distribution: AMW was determined using ultrafiltration membranes with a Amicon ${ }^{\circledR}$ cell device (Model 8200, Millipore, USA). For ultrafiltration operation, the stock humic acid solution was diluted 200 times with deionized water and the $\mathrm{pH}$ was adjusted to 7.50 using $0.05 \mathrm{~mol} \mathrm{l}^{-1} \mathrm{HCl}$. Pure nitrogen gas $(0.25-0.35 \mathrm{MPa})$ was used as the driving force. The humic acid was divided into four classes: >30, 10-30, 3-10 and <3 kDa. The dissolved organic carbon (DOC) and $\mathrm{UV}_{254}$ absorbance of each class were measured using a total organic carbon analyzer (Phoenix 8000, USA) and UV-vis 8500 spectrophotometer (Shanghai, China), respectively. The AMW distribution of the humic acid in terms of DOC and $\mathrm{UV}_{254}$ values are shown in Table 2. The humic acid was mainly consisted of high AMW constituents with fraction greater than $30 \mathrm{kDa}$ accounted for $70.1 \%$ of DOC and $86.3 \%$ of $\mathrm{UV}_{254}$ absorbance. The fractions with AMW of 10-30,3-10 and $<3 \mathrm{kDa}$ were accounted for 17.6, 3.4 and $8.9 \%$ of DOC, respectively. It can be noticed that the percentage of $\mathrm{UV}_{254}$ absorbance was not equal to that of DOC for each fraction. It can be inferred that the specific ultraviolet absorbance value (SUVA) of higher AMW fraction ( $>30 \mathrm{kDa}$ ) was greater than those of lower AMW fractions. For the fraction of $<3 \mathrm{kDa}$, no $\mathrm{UV}_{254}$ absorbance was detected.

Resin fractionation: the chemical property of the humic acid was further characterized by resin fractionation to reveal the distribution of hydrophobic or hydrophilic constituents. The fractionation operation used in this study was modified based on the method described by Chiang et al. [17]. The humic acid solution sample was the same as used for ultrafiltration.
A brief description of the procedures is as follows: the sample was passed slowly through a column $(3.5 \mathrm{~cm} \times 50 \mathrm{~cm})$ filled with $80 \mathrm{ml}$ of XAD- 8 resin at about $200 \mathrm{ml} \mathrm{h}^{-1}$. The hydrophobic base and hydrophobic neutral parts (denoted as HoB and HoN, respectively), were adsorbed on the XAD-8 resin. The effluent was collected and adjusted to $\mathrm{pH} 2.0$, and then flowed through another XAD-8 column, the hydrophobic acid (HoA) was adsorbed at this stage. Next, the effluent was fed into another column filled with XAD-4 resin, which adsorbed the weakly hydrophobic organics (WhoA), the residual organics in the final effluent was the hydrophilic fraction $(\mathrm{HiO})$. Finally, the first XAD-8 column was back washed by $0.1 \mathrm{~mol}^{-1} \mathrm{H}_{3} \mathrm{PO}_{4}$, and then $\mathrm{HoB}$ fraction could be released. During the whole operation process, the feed and effluent water volumes from each column were recorded. The DOC and $\mathrm{UV}_{254}$ absorbance of all samples were measured so that the content of each fraction could be calculated.

The resin fractionation results are also presented in Table 2. It can be seen that the major fraction was HoA, accounted for $50.2 \%$ of the total DOC and $57.1 \%$ of the total $\mathrm{UV}_{254}$ absorbance. WhoA and $\mathrm{HiO}$ fractions was 21.4 and $26.5 \%$ of total DOC, and 25.4 and $9.9 \%$ of total $\mathrm{UV}_{254}$ absorbance, respectively. These two fractions could be generally regarded as fulvic acid. Very little amount of $\mathrm{HoB}$ and no HoN were detected. Combined with the ultrafiltration fraction results, it could be deduced that the organic matter with AMW $>30 \mathrm{kDa}$ were mainly composed of hydrophobic acid and weakly hydrophobic acid fractions. While the fractions with AMW $<30 \mathrm{kDa}$ were primarily hydrophilic organics.

\subsection{Jar tests}

Synthetic test water was prepared by adding humic acid stock solution into deionized water $\left(20 \mathrm{ml}^{-1}\right)$, meanwhile, $2.0 \times 10^{-3} \mathrm{moll}^{-1} \mathrm{NaHCO}_{3}$ was added to provide a certain buffer capacity and ionic strength. The $\mathrm{pH}$ of test water was adjusted by $0.5 \mathrm{moll}^{-1} \mathrm{HCl}$ and $0.1 \mathrm{moll}^{-1} \mathrm{NaOH}$ solutions. Jar tests were performed on a program-controlled JTY-4 jar tester (Beijing, China). Test water of $500 \mathrm{ml}$ was transferred into a $800 \mathrm{ml}$ beaker; under rapid stirring of $200 \mathrm{rpm}$, predetermined amount of coagulant was dosed; after 2 min, the stirring speed was changed to $40 \mathrm{rpm}$ with a duration of $15 \mathrm{~min}$; then after 20 min of quiescent settling, sample was collected from $2 \mathrm{~cm}$ below the surface for residual turbidity (RT) (2100N Tur-

Table 2

Ultrafiltration and resin fractionation results of the test humic acid

\begin{tabular}{|c|c|c|c|c|c|c|c|}
\hline \multicolumn{2}{|c|}{$>30 \mathrm{kDa}(\%)$} & \multicolumn{2}{|c|}{$10-30 \mathrm{kDa}(\%)$} & \multicolumn{2}{|c|}{$3-10 \mathrm{kDa}(\%)$} & \multicolumn{2}{|c|}{$<3 \mathrm{kDa}(\%)$} \\
\hline DOC & $\mathrm{UV}_{254}$ & DOC & $\mathrm{UV}_{254}$ & DOC & $\mathrm{UV}_{254}$ & DOC & $\mathrm{UV}_{254}$ \\
\hline 70.1 & 86.3 & 17.6 & 8.5 & 3.4 & 5.2 & 8.9 & 0.0 \\
\hline \multicolumn{2}{|c|}{$\operatorname{HoB}(\%)$} & \multicolumn{2}{|c|}{ HoA $(\%)$} & \multicolumn{2}{|c|}{ WhoA (\%) } & \multicolumn{2}{|c|}{$\mathrm{HiO}(\%)$} \\
\hline DOC & $\mathrm{UV}_{254}$ & DOC & $\mathrm{UV}_{254}$ & DOC & $\mathrm{UV}_{254}$ & DOC & $\mathrm{UV}_{254}$ \\
\hline 1.9 & 7.6 & 50.2 & 57.1 & 21.4 & 25.4 & 26.5 & 9.9 \\
\hline
\end{tabular}

Note: original humic acid solution DOC $2.93 \mathrm{mg} \mathrm{l}^{-1}, \mathrm{UV}_{254} 0.3306 \mathrm{~cm}^{-1}$. 
bidimeter, Hach, USA) and pH (MP220 pH meter, Switzerland) measurements; at the same time, collected sample was filtered through $0.45 \mu \mathrm{m}$ membrane to measure the $\mathrm{UV}_{254}$ absorbance. The removal of $\mathrm{UV}_{254}$ absorbance was used to evaluate the coagulation efficiency in this study.

To understand the $\mathrm{Al}$ species transformation after coagulation, flocs formed under some conditions were collected and freeze-dried for solid-state ${ }^{27} \mathrm{Al}$ MAS NMR (Varian Unity Inova 300, USA) examination. The instrument settings were: resonance frequency $78.2 \mathrm{MHz}$; pulse width $0.3 \mu$ s; recycling delay time $1 \mathrm{~s}$; magic angle spinning speed $5 \mathrm{kHz}$.

\subsection{Flocculation kinetics}

The flocculation kinetics after coagulant addition was monitored by using a photometric dispersion analyzer (PDA 2000, Rank Brothers Co., UK). The principle of this monitoring technique was described in literature $[18,19]$. The PDA apparatus can give a reading called flocculation index (FI) when suspension particles passing through a flow-through cell. FI is sensitive to particle size and can be effectively utilized to describe the aggregation progress of fine particles, such as the initial aggregation, breakage, and re-aggregation behaviors of particles. The flow rate was controlled by a peristaltic pump with rotation speed of $30 \mathrm{rpm}$. The coagulation procedures were the same as jar tests.

\section{Results}

\subsection{Coagulation behaviors under neutral $\mathrm{pH}$}

The removal of humic acid by different coagulants was first examined under $\mathrm{pH}$ of 7.50. As shown in Fig. 2, the turbidity after coagulation increased first and then decreased with the increase of coagulant dosage, but the $\mathrm{UV}_{254}$ removal increased continuously and could reach $100 \%$ at high dosages for all coagulants. It can be seen that $\mathrm{PACl}$ and $\mathrm{Al}_{13}$ exhibited very similar coagulation behaviors in terms of residual turbidity, $\mathrm{UV}_{254}$ removal and post-coagulation $\mathrm{pH}$ values. However, the $\mathrm{UV}_{254}$ removal of $\mathrm{AlCl}_{3}$ was much higher than those of $\mathrm{PACl}$ and $\mathrm{Al}_{13}$ before reaching complete removal. On the other hand, the maximal residual turbidity associated with $\mathrm{AlCl}_{3}$ appeared at lower dosages than those with $\mathrm{PACl}$ and $\mathrm{Al}_{13}$.

It was found that no appreciable floc was formed if the dosage was less than that corresponding to maximal turbidity value, which indicated that only small particles were formed within low dosage range. These small particles were not settable but could be intercepted by filter membrane. When the dosage passed this point, large and settable flocs were formed. The required dosage for floc formation was: $\mathrm{AlCl}_{3}<\mathrm{PACl} \approx \mathrm{Al}_{13}$.

The flocs formed by $\mathrm{AlCl}_{3}$ were much larger than those formed by $\mathrm{PACl}$ and $\mathrm{Al}_{13}$ (Fig. 3). At dosage of $18 \times 10^{-5} \mathrm{moll}^{-1}$, the systems associated with $\mathrm{PACl}$ and $\mathrm{Al}_{13}$ did not form any detectable flocs, but large flocs were developed rapidly in the system with $\mathrm{AlCl}_{3}$. At a higher dosage of $22 \times 10^{-5} \mathrm{moll}^{-1}$, flocs appeared in the systems of PACl and $\mathrm{Al}_{13}$, but they were much smaller than those formed by $\mathrm{AlCl}_{3}$.
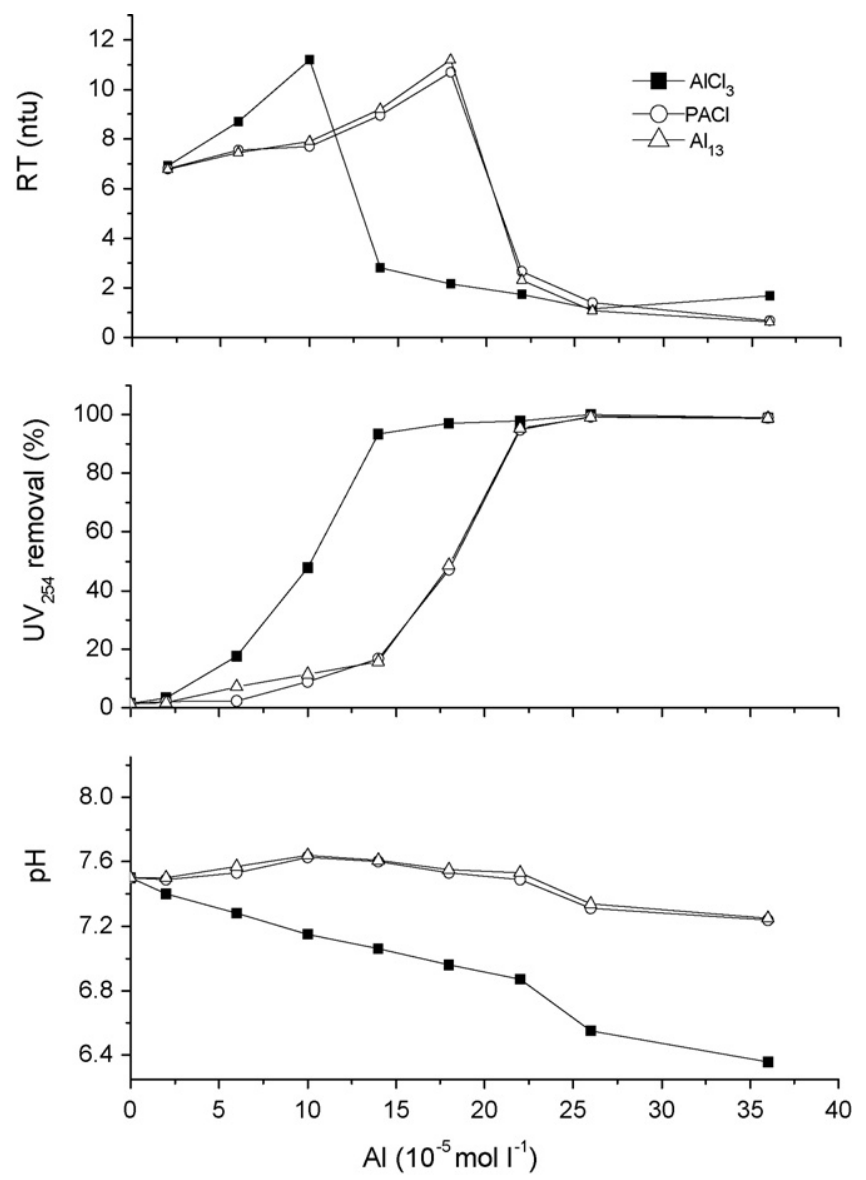

Fig. 2. Residual turbidity (RT), $\mathrm{UV}_{254}$ removal, and $\mathrm{pH}$ as function of coagulant dosage.
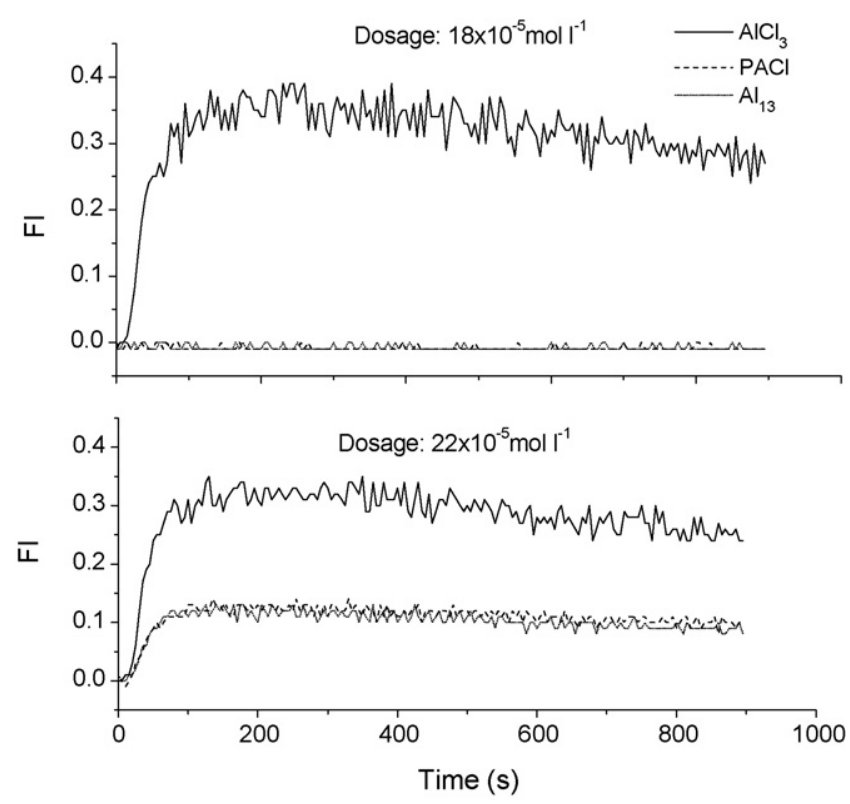

Fig. 3. Flocculation kinetics of three coagulants at two different dosages. 


\subsection{Effect of $\mathrm{pH}$ on coagulation performance}

\subsubsection{Coagulation with $\mathrm{pH}$ changes at constant dosage}

In order to investigate the effect of $\mathrm{pH}$ on humic acid coagulation performance, the test water $\mathrm{pH}$ was adjusted to different levels and the dosage was fixed at $10 \times 10^{-5} \mathrm{moll}^{-1}$. The changes of residual turbidity and $\mathrm{UV}_{254}$ removal with $\mathrm{pH}$ are shown in Fig. 4. For all three coagulants, the $\mathrm{UV}_{254}$ removal increased with the decrease of $\mathrm{pH}$ and nearly complete removal was achieved when $\mathrm{pH}$ was less than 4.50 . The removals by $\mathrm{PACl}$ and $\mathrm{Al}_{13}$ were almost the same and significantly lower than that by $\mathrm{AlCl}_{3}$ when the $\mathrm{pH}$ was greater than 4.50. However, the variations of residual turbidity with $\mathrm{pH}$ were rather complicated. When the $\mathrm{pH}$ was reduced from 8.50 to 4.50 , the residual turbidities corresponding to three coagulants all experienced increase and subsequent decrease. During the turbidity increasing phase, no settable floc was developed. With further $\mathrm{pH}$ decreasing, large flocs were well formed, and residual turbidities were lowered accordingly. However, it was observed that the turbidity pertinent to $\mathrm{AlCl}_{3}$ increased again when the $\mathrm{pH}$ was reduced further from 4.50. At $\mathrm{pH}$ of 2.50 , no appreciable floc was formed. Since the filtered sample still exhibited nearly complete $\mathrm{UV}_{254}$ removal, it could be inferred that small particles existed in the system, but they might be re-stabilized due to electrical charge reversion. No obvious re-stabilization phenomenon was observed in the cases of $\mathrm{PACl}$ and $\mathrm{Al}_{13}$.

\subsubsection{Coagulation with dosage changes at $\mathrm{pH}$ of 5.50 and} 3.50

The $\mathrm{UV}_{254}$ removal and residual turbidity variation as function of dosage were obtained at $\mathrm{pH}$ of 5.50 and 3.50, which represented the optimal and low $\mathrm{pH}$ values, respectively (Fig. 5). At $\mathrm{pH} 5.50$, the $\mathrm{UV}_{254}$ removal by $\mathrm{AlCl}_{3}$ was much higher than those by $\mathrm{PACl}$ and $\mathrm{Al}_{13}$. However, such difference was greatly reduced at $\mathrm{pH}$ of 3.50 . In terms of the residual tur-
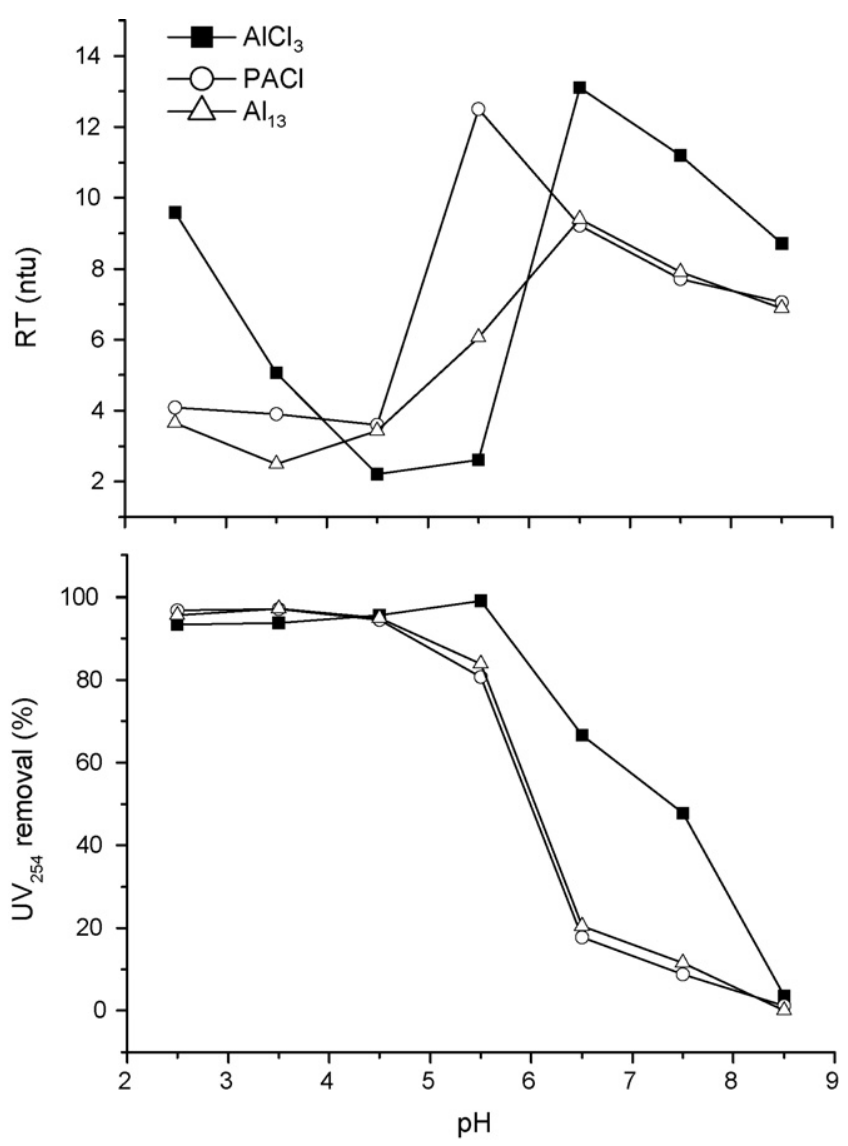

Fig. 4. Effect of $\mathrm{pH}$ on residual turbidity and $\mathrm{UV}_{254}$ removal at constant dosage of $10 \times 10^{-5} \mathrm{moll}^{-1}$

bidity after coagulation, it is clear that severe re-stabilization phenomenon occurred with the increase of $\mathrm{AlCl}_{3}$ dosage. While at high dosages, only slight turbidity increase was found for $\mathrm{PACl}$ and no re-stabilization was observed for $\mathrm{Al}_{13}$.
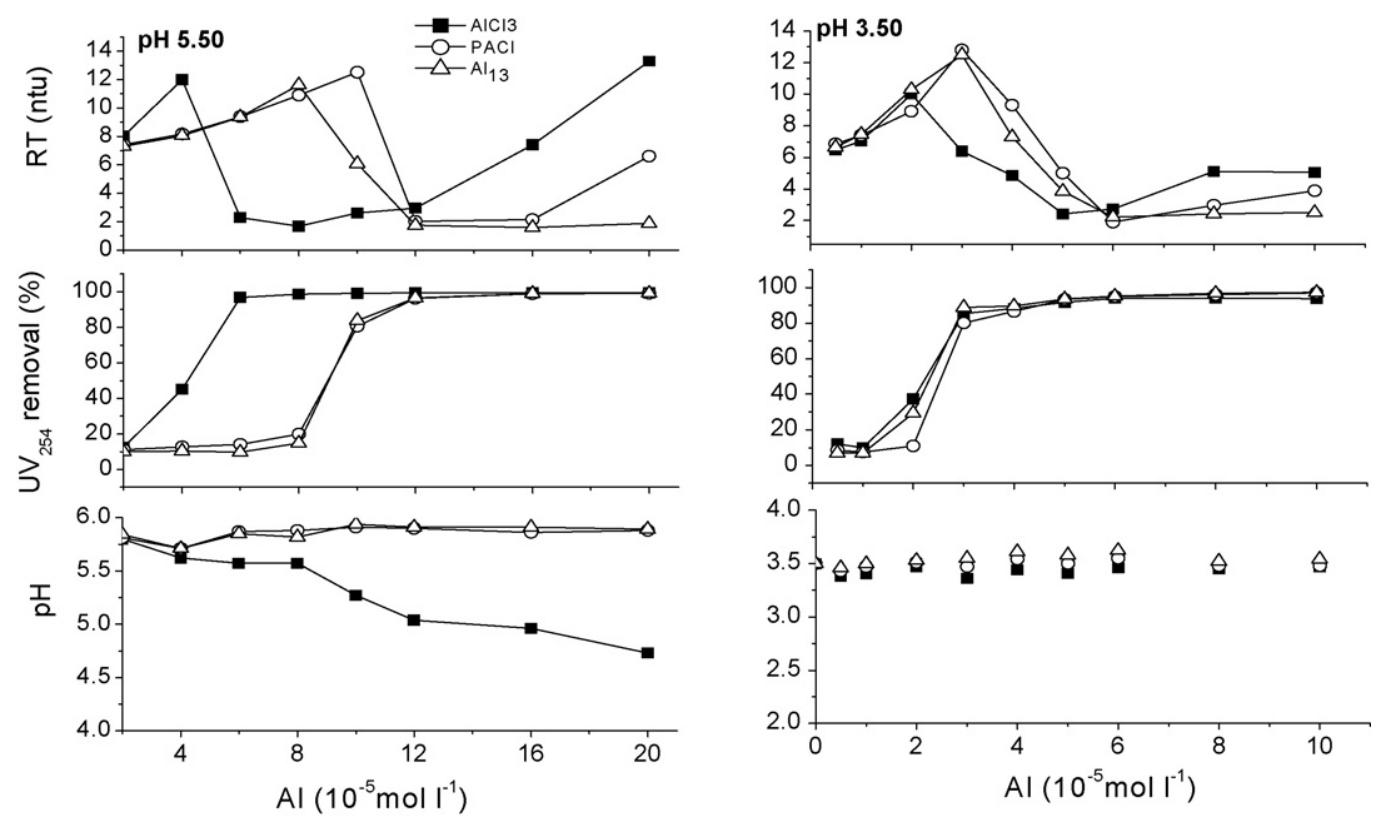

Fig. 5. Coagulation as function of dosage at $\mathrm{pH} 5.50$ and 3.50. 
The $\mathrm{pH}$ after coagulation decreased continuously with the increase of $\mathrm{AlCl}_{3}$ dosage when the original $\mathrm{pH}$ was 5.50, but there was no significant $\mathrm{pH}$ variation before and after coagulation when the original $\mathrm{pH}$ was 3.50 .

It should be pointed out that the strong re-stabilization tendency associated with $\mathrm{AlCl}_{3}$ is contradictory to the common knowledge on the charge neutralization abilities of different $\mathrm{Al}$ species when coagulation is used to remove mineral colloids, which will be discussed later.

\subsubsection{Dosage required for complete $U V_{254}$ removal}

As mentioned above, the $\mathrm{UV}_{254}$ removal with dosage increased rapidly once observable flocs were developed, which was reflected by the steep rise of corresponding curves. If the point where the extrapolated steep portion of the $\mathrm{UV}_{254}$ removal curve intersects the $100 \%$ removal line was chosen as the required coagulant dosage for complete $\mathrm{UV}_{254}$ removal (RCDC), the coagulation capacity of different coagulant could be compared quantitatively. Fig. 6 illustrates the RCDC values of three coagulants at different $\mathrm{pH}$ levels. Obviously, $\mathrm{PACl}$ and $\mathrm{Al}_{13}$ exhibited the same coagulation capacity. And the RCDC values decreased with the decrease of $\mathrm{pH}$ : from $\mathrm{pH} 7.50$ to 5.50, the $\mathrm{RCDC}$ values of $\mathrm{AlCl}_{3}$ and $\mathrm{PACl} / \mathrm{Al}_{13}$ decreased 58 and $48 \%$, respectively; from $\mathrm{pH} 5.50$ to 3.50 , the corresponding decreases were 44 and $72 \%$, accordingly.

At $\mathrm{pH}$ of 7.50 and $5.50, \mathrm{AlCl}_{3}$ exhibited much higher coagulation capability than $\mathrm{PACl}$ and $\mathrm{Al}_{13}$ : the $\mathrm{RCDC}$ values of $\mathrm{AlCl}_{3}$ were only 66 and $53 \%$ of those with $\mathrm{PACl} / \mathrm{Al}_{13}$ at $\mathrm{pH} 7.50$ and 5.50 , respectively. It implies that the coagulant constituted of monomeric $\mathrm{Al}$ species could have higher coagulation capacity than those constituted of preformed $\mathrm{Al}$ species in terms of large molecular humic acid removal.

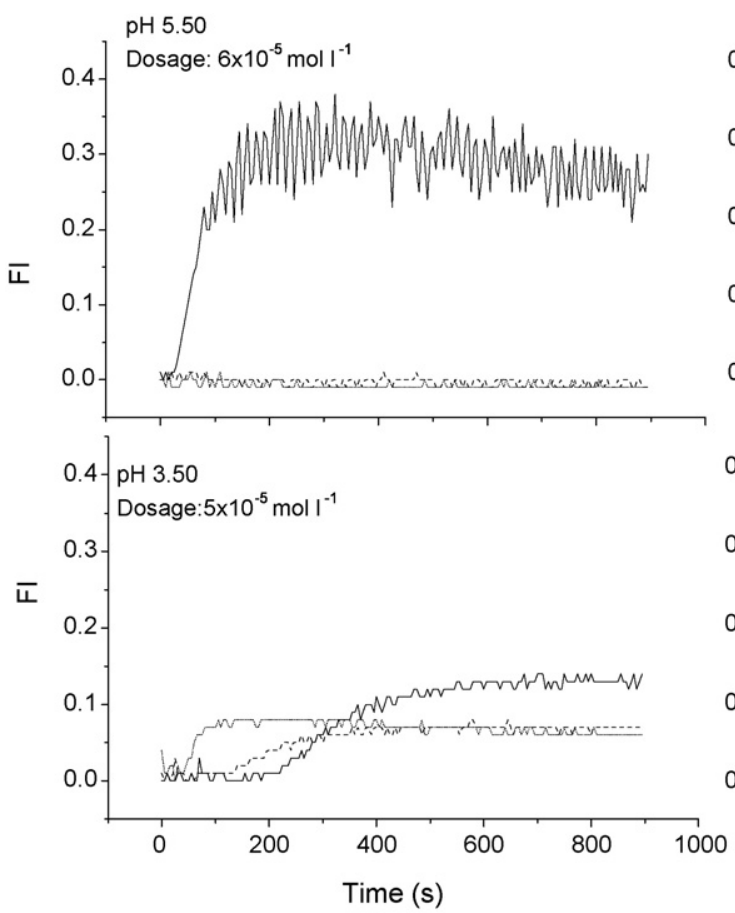

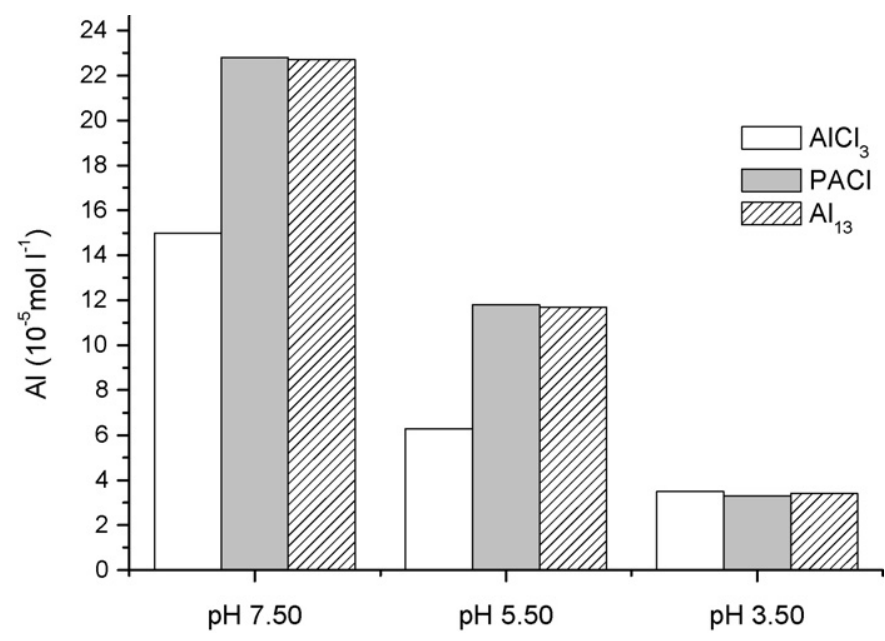

Fig. 6. Required coagulant dosage for complete $\mathrm{UV}_{254}$ removal at different $\mathrm{pH}$ levels.

\subsubsection{Coagulation kinetics at $\mathrm{pH}$ of 5.50 and 3.50}

The coagulation kinetics at $\mathrm{pH} 5.50$ and 3.50 with different dosages are shown in Fig. 7. At $\mathrm{pH} 5.50$ and dosage $6 \times 10^{-5} \mathrm{moll}^{-1}$, large flocs were formed in the case of $\mathrm{AlCl}_{3}$ while no appreciable flocs were observed with $\mathrm{PACl}$ and $\mathrm{Al}_{13}$. If the dosage increased to $12 \times 10^{-5} \mathrm{moll}^{-1}$, small flocs was developed by $\mathrm{PACl}$ and $\mathrm{Al}_{13}$. However, in the case of $\mathrm{AlCl}_{3}$, the size of flocs decreased compared to that at lower dosage $\left(6 \times 10^{-5} \mathrm{moll}^{-1}\right)$, which indicated that re-stabilization might have occurred. In addition, the floc size formed by $\mathrm{AlCl}_{3}$ decreased slowly with the elapse of time.

When the test water $\mathrm{pH}$ was reduced to 3.50 , the flocculation kinetics with $\mathrm{AlCl}_{3}$ exhibited much different features compared to that at $\mathrm{pH} 5.50$ : the sizes of flocs were much smaller and there

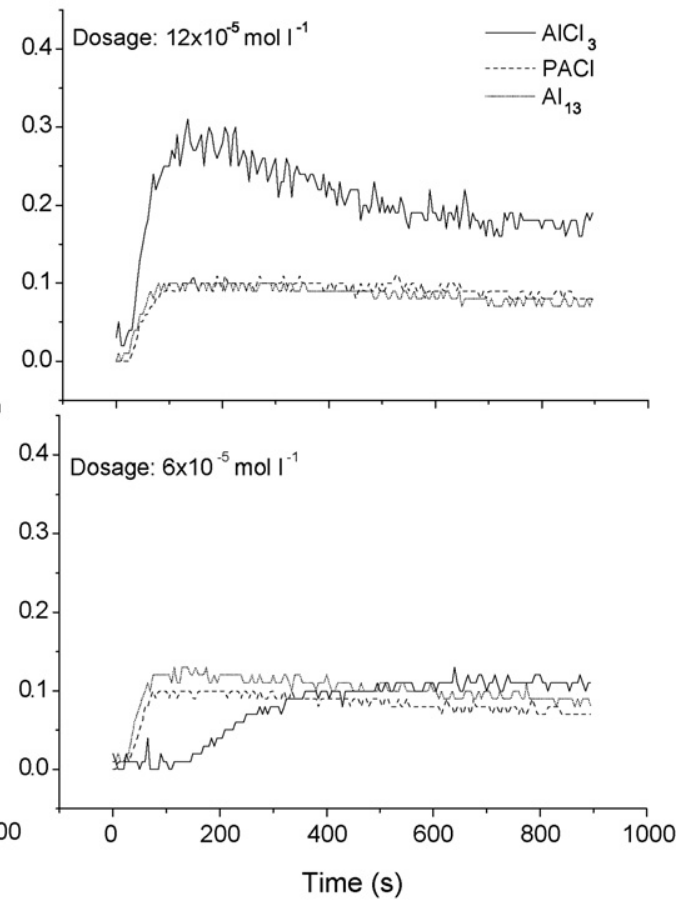

Fig. 7. Coagulation kinetics at $\mathrm{pH}$ of 5.50 and 3.50 with different dosages. 
existed a time lag (about $3 \mathrm{~min}$ ) between dosing and formation of appreciable flocs. However, the $\mathrm{pH}$ reduction did not influence the flocculation kinetics of $\mathrm{PACl}$ and $\mathrm{Al}_{13}$ significantly.

\section{Discussion}

\subsection{Interactions between humic acid and different Al species}

As a typical kind of IPFs, PACl has the advantage of being more effective at lower temperatures and a broad $\mathrm{pH}$ range due to the presence of relatively stable preformed Al species (particularly $\mathrm{Al}_{13}$ ). However, the coagulation/flocculation mechanisms of PACl have not been clearly understood. In the aspect of removing mineral colloids from water, the performance of $\mathrm{PACl}$ was mostly explained by the high positive charge associated with preformed $\mathrm{Al}$ species and the consequent high ability in neutralizing the negative charge of colloids [1].

It has been well known that humic substances can be effectively removed from water by hydrolyzing coagulants, such as aluminum and ferric salts. But it is still uncertain if the coagulants with preformed $\mathrm{Al}$ (or ferric) species are superior to conventional coagulants in removing humic substances. As shown in Table 1, the three coagulants used in this study have distinct speciation characteristics: $\mathrm{AlCl}_{3}$ dominated by monomeric $\mathrm{Al}$ species, $\mathrm{Al}_{13}$ with high purity and $\mathrm{PACl}$ with mixed species of $\mathrm{Al}_{13}$ and colloidal $\mathrm{Al}$ species. After dosing into water, monomeric Al species will subject to a series of hydrolysis to form mutilnuclear species with different polymerization degree and finally form amorphous hydroxide solids. However, the $\mathrm{Al}_{13}$ species can be relatively stable after dosing and no hydroxide can be formed during the coagulation time scale [8].

Based on the above results, $\mathrm{AlCl}_{3}$ demonstrated the most effective removal of humic acid, meanwhile the coagulation behaviors of $\mathrm{PACl}$ and $\mathrm{Al}_{13}$ were much similar. It can be concluded that the roles of preformed and non-preformed $\mathrm{Al}$ species in humic acid removal were distinctly different from those in mineral colloid removal. The high positive charge of preformed $\mathrm{Al}$ species, particularly $\mathrm{Al}_{13}$, did not exhibit high coagulation efficiency in humic acid removal. Moreover, with the increase of dosage, strong re-stabilization occurred in the system of $\mathrm{AlCl}_{3}$ dosed, while $\mathrm{Al}_{13}$ did not lead to re-stabilization (Fig. 5).

As characterized by ultrafiltration and resin fractionation, the humic acid used in this study was mainly consisted of large molecular and hydrophobic fractions, therefore it should be more inclined to be removed by forming insoluble complexes with $\mathrm{Al}$ species.

Under a given $\mathrm{pH}$, there should be a certain charge density for the humic acid due to the dissociation of carboxylic and phenolic groups. But the interactions between the negatively charged functional groups and cationic Al species might not follow stoichiometric relations. Due to their relatively larger size and higher positive charge, the association of preformed $\mathrm{Al}$ species with humic acid could be stronger and such interactions might be able to induce reconformation of long humic acid molecules around the preformed $\mathrm{Al}$ species. Consequently the positive charges of preformed $\mathrm{Al}$ species can be greatly shielded and such interac- tions are more approximate to stoichiometric relations. On the other hand, the reconformation of humic acid might be a reason of the smaller flocs formed by preformed $\mathrm{Al}$ species.

However, the interactions of non-preformed $\mathrm{Al}$ species with humic acid could be much weaker and might not be able to induce reconformation of humic acid molecules. Then partial neutralization of the negatively charged sites can lead to destabilization of humic acid and no stoichoimetric relation exists for this kind of interaction. Hence, it is possible that the removal of humic acid by non-preformed $\mathrm{Al}$ species could be achieved at lower Al dosages and re-stabilization could occur at high dosages.

The reactions of humic acid with preformed or nonpreformed Al species involve different pathways. It was reported that pre-hydrolyzed $\mathrm{Al}$ species could bind selectively to carboxylic groups at $\mathrm{pH} 6$ and to phenolic moieties at $\mathrm{pH} 8$ [20]. At higher coagulant concentrations, the remaining functional groups also interact with pre-hydrolyzed $\mathrm{Al}$ species. However, it was observed [21] that the tetrahedral $\mathrm{Al}$ in the $\mathrm{Al}_{13}$-humic acid complexes could gradually be converted to octahedral $\mathrm{Al}$, indicating that $\mathrm{Al}_{13}$ in $\mathrm{Al}_{13}-\mathrm{HA}$ complexes could be decomposed into Al-HA complexes with time. $\mathrm{Lu}$ et al. also found that the existence of humic acid could significantly inhibit the formation of $\mathrm{Al}_{13}$ when base was added to $\mathrm{Al}$ solution [2].

In this study, the humic acid flocs formed by $\mathrm{AlCl}_{3}$ and $\mathrm{Al}_{13}$ at test water $\mathrm{pH}$ of 7.50 and $\mathrm{Al}$ dosage of $22 \times 10^{-5} \mathrm{moll}^{-1}$ was collected and freeze-dried to obtain the solid-state ${ }^{27} \mathrm{Al}$ MAS NMR spectra (Fig. 8). It is clear that no $\mathrm{Al}_{13}$ structure existed in the flocs formed by dosing $\mathrm{AlCl}_{3}$, and the only signal at $0 \mathrm{ppm}$ indicated the $\mathrm{Al}$ species was octahedrally coordinated complexes (Fig. 8a). Although tetrahedrally coordinated Al still existed in the flocs formed by $\mathrm{Al}_{13}$, part of $\mathrm{Al}$ had converted to octahedral $\mathrm{Al}-\mathrm{HA}$ complexes after coagulation. It confirms that $\mathrm{Al}_{13}-\mathrm{HA}$ complexes were not stable, and the $\mathrm{Al}_{13}$ could be decomposed by humic acid with time. It should be pointed

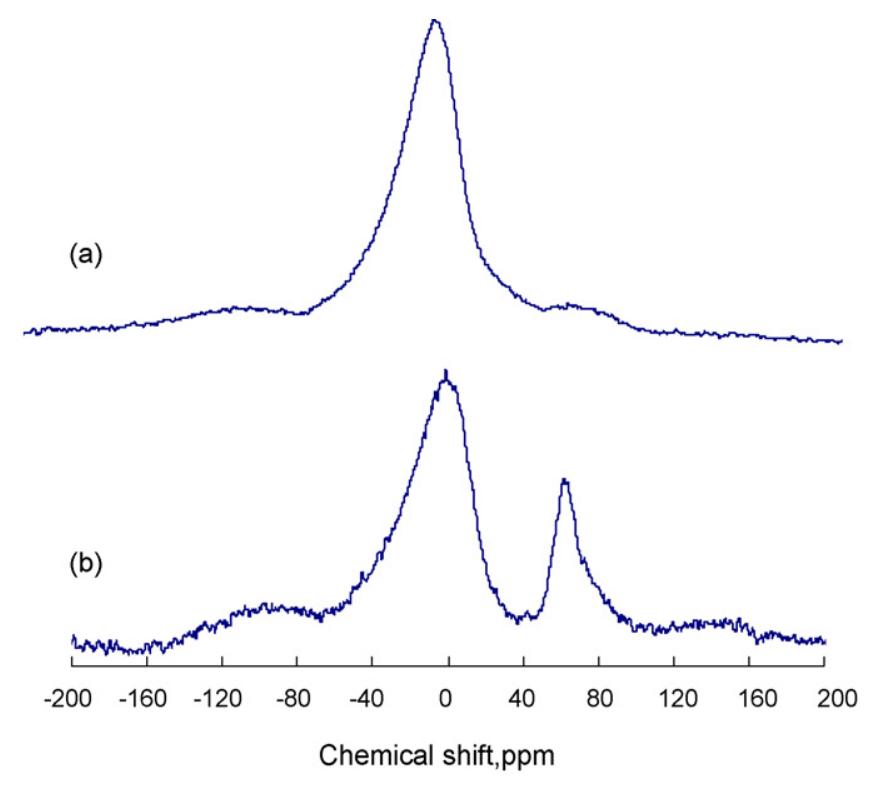

Fig. 8. Solid-state ${ }^{27} \mathrm{Al}$ NMR spectra of freeze-dried humic acid flocs formed by (a) $\mathrm{AlCl}_{3} ;$ (b) $\mathrm{Al}_{13}$. 
out that the $\mathrm{Al}_{13}$ decomposition did not induce significant $\mathrm{pH}$ changes (Fig. 2) during coagulation process, which indicated that the $\mathrm{Al}_{13}$ decomposition and structure re-arrangement might take place at the same time.

\subsection{Influences of $\mathrm{pH}$ on $\mathrm{Al}$ species and the structure of humic acid}

The effect of $\mathrm{pH}$ on the coagulation of humic acid could be interpreted from two aspects. Firstly, with the decrease of $\mathrm{pH}$, the carboxylic and phenolic groups on the humic acid molecular chain will become less negatively charged due to protonation reactions, therefore, less coagulant will be required to achieve neutralization or form insoluble complexes (Fig. 6). Secondly, $\mathrm{pH}$ can greatly affect the hydrolysis process of monomeric $\mathrm{Al}$ species. At higher $\mathrm{pH}$, the reactions of monomeric $\mathrm{Al}$ complexing with humic acid and further hydrolyzing to form polymeric or hydroxide precipitate could occur simultaneously. Therefore, at least two mechanisms might be involved in the coagulation of humic acid: precipitation by forming insoluble complexes and adsorption of humic acid onto hydroxide solids. While at lower $\mathrm{pH}$ (e.g. 3.5), further hydrolysis of monomeric $\mathrm{Al}$ is greatly inhibited after dosing (as indicated in Fig. 5, no significant $\mathrm{pH}$ depression with the increase of dosage), formation of insoluble HA-Al complexes become the primary mechanism of humic acid removal. Moreover, the flocs formed at lower $\mathrm{pH}$ of 3.50 were smaller than those formed through the combination of complex formation and adsorption.

\section{Conclusion}

Although preformed polymeric $\mathrm{Al}$ coagulants are superior to conventional ones in removing mineral colloids, they might not be effective in removing dissolved organic matter. As revealed in this study, when large molecular and hydrophobic humic acid was treated, the coagulation efficiency of preformed $\mathrm{Al}$ species $\left(\mathrm{Al}_{13}\right.$ and colloidal species) was much less than that of conventional $\mathrm{Al}$ salt. The flocs formed by preformed $\mathrm{Al}$ species were smaller than those formed by conventional Al salt.

Decreasing $\mathrm{pH}$ could significantly reduce the coagulant dosage required for complete $\mathrm{UV}_{254}$ removal regardless of the $\mathrm{Al}$ speciation differences.

Unlike the coagulation of mineral colloidal particles, forming insoluble complexes could be one of the primary mechanisms involved in humic acid removal. The complexes formed by $\mathrm{Al}_{13}$ and humic acid were not stable, and the $\mathrm{Al}_{13}$ structure could be decomposed in the presence of humic acid.

\section{Acknowledgement}

This work was supported by the National Natural Science Foundation of China (Grant No. 20537020).

\section{References}

[1] J. Duan, J. Gregory, Coagulation by hydrolyzing metal salts, Adv. Colloid Interface Sci. 100-102 (2003) 475-502.

[2] X. Lu, Z. Chen, X. Yang, Spectroscopic study of the aluminum speciation in removing humic substances by Al coagulation, Water Res. 33 (1999) 3271-3280

[3] B.A. Dempsey, R.M. Ganho, C.R. O'Melia, The coagulation of humic substances by means of aluminum salts, J. Am. Water Works Assoc. 76 (4) (1984) 141-150.

[4] J.K. Edzwald, Coagulation in drinking water treatment—particles, organics and coagulants, Water Sci. Technol. 27 (1993) 21-35.

[5] Y. Matsui, A. Yuasa, Y. Furaya, T. Kamei, Dynamic analysis of coagulation with alum and PACl, J. Am. Water Works Assoc. 90 (10) (1998) 96106.

[6] W.P. Cheng, Comparison of hydrolysis/coagulation behavior of polymeric and monomeric iron coagulants, Chemosphere 47 (2002) 963969

[7] S. Sinha, Y. Yoon, G. Amy, J. Yoon, Determining the effectiveness of conventional and alternative coagulants through effective characterization schemes, Chemosphere 57 (2004) 1115-1122.

[8] D. Wang, W. Sun, Y. Xu, H. Tang, J. Gregory, Speciation stability of inorganic polymer flocculant-PACl, Colloid Surf. A 243 (2004) 1-10.

[9] K.N. Exall, G.W. Vanloon, Using coagulants to remove organic matter, J. Am. Water Works Assoc. 92 (11) (2000) 93-102.

[10] Y.H. Shen, B.A. Dempsey, Synthesis and speciation of polyaluminum chloride for water treatment, Environ. Int. 24 (1998) 899-910.

[11] H. Tang, Z. Luan, The differences of behavior and coagulating mechanism between inorganic polymer flocculants and traditional coagulants, in: H.H. Hahn, E. Hoffmann, H. Ødegaard (Eds.), Chemical Water and Waste Water Treatment, Springer, Berlin, 1996, pp. 83-93.

[12] A.I. Zouboulis, G. Traskas, Comparable evaluation of various commercially available aluminum-based coagulants for the treatment of surface water and for the post-treatment of urban waste water, J. Chem. Technol. Biotechnol. 80 (2005) 1136-1147.

[13] L. Rizzo, V. Belgiorno, M. Gallo, S. Meric, Removal of THM precursors from a high-alkaline surface water by enhanced coagulation and behavior of THMFP toxicity on D. magna, Desalination 176 (2005) 177188.

[14] C.R. O'Melia, W.C. Becker, K.K. Au, Removal of humic substances by coagulation, Water Sci. Technol. 40 (1999) 47-54.

[15] M.R. Collins, G.L. Amy, C. Steelink, Molecular weight distribution, carboxylic acidity, and humic substances content of aquatic organic matter: implications for removal during water treatment, Environ. Sci. Technol. 20 (1986) 1028-1032.

[16] B. Shi, G. Li, D. Wang, H. Tang, Separation of Al13 from polyaluminum chloride by sulfate precipitation and nitrate metathesis, Sep. Purif. Technol. 54 (2007) 88-95.

[17] P.C. Chiang, E.E. Chang, C.H. Liang, NOM characteristics and treatabilities of ozonation processes, Chemosphere 46 (2002) 929-936.

[18] J. Gregory, Turbidity fluctuations in flowing suspensions, J. Colloid Interface Sci. 105 (1985) 357-371.

[19] D. Wang, H. Tang, J. Gregory, Relative importance of charge neutralization and precipitation on coagulation of kaolin with PACl: effect of sulfate, Envion. Sci. Technol. 36 (2002) 1815-1820.

[20] V. Kazpard, B.S. Lartiges, C. Frochot, J.B. d'Esppinose, Fate of coagulant species and conformational effects during the aggregation of a model of humic substances with $\mathrm{Al}_{13}$ polycations, Water Res. 40 (2006) 19651974.

[21] S. Hiradate, N.U. Yamaguchi, Chemical species of Al reacting with soil humic acids, J. Inorg. Biochem. 97 (2003) 26-31. 